\title{
The influence of the economic and social environment on deliberate self-harm and suicide: an ecological and person-based study
}

\author{
K. HAWTON, ${ }^{1}$ L. HARRISS, K. HODDER, S. SIMKIN AND D. GUNNELL \\ From the Centre for Suicide Research, University of Oxford Department of Psychiatry, \\ Warneford Hospital and Department of Public Health, Oxfordshire Health Authority, Oxford; \\ and Department of Social Medicine, University of Bristol
}

\begin{abstract}
Background. Geographic variations in the incidence of deliberate self-harm (DSH) and suicide have been shown to be associated with area-based measures of socio-economic deprivation and social fragmentation. Previous studies have been subject to methodological limitations. None has investigated whether ecological associations are reflected in characteristics of individuals involved in suicidal behaviour.

Methods. DSH patients presenting to a general hospital between 1985 and 1995 and suicides (including open verdicts) from the same catchment area were studied. Mean annual rates of DSH and suicide by gender were calculated for electoral wards. The wards were amalgamated into 20 groups according to their ranking for socio-economic deprivation (Townsend) and social fragmentation scores. Associations of these variables with DSH and suicide rates were investigated. Characteristics of DSH patients living in ward groups with the highest and lowest socio-economic deprivation and social fragmentation scores were compared.

Results. Socio-economic deprivation was associated with DSH rates among males $(r=0 \cdot 89)$ and females $(r=0 \cdot 87)$. After controlling for social fragmentation the associations remained relatively strong, particularly in young males. Associations with social fragmentation in both genders (males, $r=0.83$; females, $r=0.86$ ) were attenuated after controlling for socio-economic deprivation. For suicide, the only significant association was with socio-economic deprivation in males $(r=0.79)$, but this was attenuated after controlling for social fragmentation. The characteristics of individual DSH patients reflected those of the areas where they lived.
\end{abstract}

Conclusions. Reducing socio-economic deprivation and its associated problems may be an important strategy in the prevention of suicidal behaviour, especially in young men.

\section{INTRODUCTION}

The influence of the socio-economic environment on population levels of suicide and deliberate self-harm (attempted suicide) has been the subject of long-standing research interest (Durkheim, 1897/1951; Platt \& Hawton, 2000). This line of research is important in that any observed associations can suggest the need for

1 Address for correspondence: Professor Keith Hawton, Centre for Suicide Research, University of Oxford Department of Psychiatry, Warneford Hospital, Oxford OX3 7JX. social policy measures for prevention of suicidal behaviour and can identify geographic areas which may benefit from targeted interventions.

Rates of suicidal behaviour, particularly deliberate self-harm (DSH), are higher in manual occupational social groups and the unemployed (Platt \& Kreitman, 1984; Hawton \& Rose, 1986; Kreitman et al. 1991; Lewis \& Sloggett, 1998; Platt \& Hawton, 2000). Rates of suicide in young people in Britain and Europe have been shown to co-vary over time with rates of unemployment (Pritchard, 1992; Gunnell et al. 
1999). Being in debt was linked to both suicidal ideation and DSH in a Finnish community study (Hintikka et al. 1998). Several studies have shown that areas characterized by high levels of socio-economic deprivation have increased rates of suicide and DSH (Gunnell et al. 1995; Congdon, 1996). Furthermore, area characteristics may act together with individual characteristics to influence suicide risk; for example, after adjusting for deprivation, the risk of suicide in different ethnic groups appears to vary inversely with local relative ethnic group density (Neeleman \& Wessely, 1999).

Durkheim $(1897 / 1951)$ related suicide rates to levels of social integration or fragmentation. In an ecological analysis in London, Congdon (1996) found that rates of both suicide and DSH were associated with both socio-economic deprivation (Townsend score) and social fragmentation (anomie score), but that this effect varied with age and gender. Whitley et al. (1999) demonstrated that higher suicide rates in the 633 parliamentary constituencies of Great Britain were associated with higher levels of social fragmentation, and that this association was independent of socio-economic deprivation. The analysis also suggested that areas experiencing the greatest absolute increase in social fragmentation over the years studied (1981-1991) had the greatest increase in suicide, indicating the possible aetiological significance of this factor.

There are several limitations to previous studies of these issues. Neither Gunnell et al. (1995) nor Congdon (1996) included data on DSH patients not admitted to hospital, and the possible effects of cross-boundary admissions were not assessed. This can have particularly important implications for localities at the edge of a catchment area. The geographical units studied vary in size from aggregations of wards (Gunnell et al. 1995) up to whole countries (Pritchard, 1992). Larger aggregates will include and simplify wide variations in social and economic conditions. Lastly, and perhaps most importantly, all investigations to date have been ecological studies. Associations at the area-level may not, however, be relevant at the level of individuals (i.e. the ecological fallacy; Greenland \& Morgenstern, 1989).

We have conducted a study in the Oxford area to determine whether some of the results of the above studies could be replicated. We have examined the associations of measures of both socio-economic deprivation and social fragmentation with rates of DSH presentations to a general hospital and local rates of suicide. We have also investigated whether the associations between these measures vary with gender and age. Data collected on individual DSH patients have been used to take this area of work further. We have examined whether any association detected at the area-level between measures of either socio-economic deprivation and/or social fragmentation and rates of suicidal behaviour is reflected at the individual level.

\section{METHOD \\ Subjects \\ Deliberate self-harm patients}

These were all patients aged 15 years and over resident in the study catchment area (see below), who presented to the main general hospital in Oxford for deliberate self-harm (DSH, i.e. selfpoisoning or self-injury) between 1 January 1985 and 31 December 1995. These subjects were identified using the Oxford Monitoring System for Attempted Suicide based at the John Radcliffe Hospital in Oxford (Hawton et al. 1997). The monitoring system identifies all patients either through assessment by members of the general hospital psychiatric service or, for non-assessed patients, from scrutiny of records of presentations to the Accident and Emergency Department. We have demonstrated that this produces comprehensive data (Sellar et al. 1990) and that the findings are comparable with those from other areas in the United Kingdom (e.g. Platt et al. 1988).

For all patients assessed by the general hospital psychiatric service the clinicians involved complete a standardized recording form. This includes socio-demographic information, postcode, clinical details, and identification of each patient's problems preceding the act of selfharm.

\section{Suicides}

These included all individuals aged 15 years and over, resident in the study catchment area, who died between 1 January 1985 and 31 December 1995 and whose deaths received a coroner's 
verdict of suicide or undetermined cause (open verdict). The open verdicts were included because it is known that the majority of these are probable suicides (Charlton et al. 1992). We only excluded those cases for which the coroner's death register clearly indicated a cause other than suicide (e.g. mesothelioma possibly due to asbestos poisoning). The deaths of the included subjects will subsequently be referred to as 'suicides'. The individuals who died in Oxfordshire were identified from the death register of the Oxford coroner. Those residents whose deaths occurred outside Oxfordshire were identified from the Oxford Record Linkage System (1985-94) and the Public Health Mortality File (Office for National Statistics, 1995). Postcodes were allocated to each individual on the basis of their place of residence at the time of death.

\section{Catchment area}

The unit of analysis in this study was the electoral ward, which is composed of smaller enumeration districts (EDs). Some EDs are classified as 'special' because the majority of their inhabitants reside elsewhere for the purposes of the Census. These include large communal establishments such as hospitals, boarding schools and university colleges. All these special EDs were excluded from the analysis. Some wards on the periphery of Oxfordshire are in the catchment areas of either a small general hospital in the north of the county or hospitals of neighbouring health authorities. We included in our analyses only those wards from which at least $91 \%$ of all admissions to any hospital for adverse effects of drugs (most of which are equivalent to deliberate self-poisoning admissions (Sellar et al. 1990)), were admitted to the John Radcliffe Hospital (data based on routine hospital datasets). Of the 144 wards within Oxfordshire, 103 were included in the study.

\section{Socio-economic deprivation}

The Townsend Index was used as the measure of socio-economic deprivation. This is a censusderived score used nationally as an indicator of socio-economic deprivation. The variables used to calculate the index are: (i) proportion of households that are not owner occupied; (ii) proportion of households with no car; (iii) proportion of overcrowded households; (iv) proportion of unemployed but economically active persons. These variables were obtained from the 1991 Census. The $z$ scores for each electoral ward were calculated using the mean and standard deviation of each variable for the county of Oxfordshire. The $z$ scores of the four variables were summed to produce a Townsend Index score for every ward. Higher positive Townsend scores indicate greater socio-economic deprivation.

\section{Social fragmentation}

Our measure of social fragmentation was based on Congdon's (1996) 'anomie' score. This is derived from four census variables: (i) population turnover - proportion of residents with a different address one year before the 1991 Census; (ii) proportion of single person households; (iii) proportion of non-married adults; and (iv) proportion of persons in privately rented accommodation. Scores for individual wards were calculated using the same method as applied to the Townsend Index variables. Higher positive scores reflect greater social fragmentation. We have used the term 'social fragmentation' throughout as the extent to which Congdon's measure reflects Durkheim's original concept of anomie is questionable.

\section{Characteristics of DSH patients}

Data from the Oxford Monitoring System for Attempted Suicide were examined to determine whether characteristics of DSH patients reflected the levels of deprivation and/or social fragmentation of the areas in which they lived. We compared characteristics of patients resident in the two ward groups with the highest socioeconomic deprivation scores (see above) with those of patients from the two ward groups with the lowest scores, and likewise for patients living in the two ward groups with the highest social fragmentation scores and the two with the lowest social fragmentation scores. The specific patient characteristics that were examined were: employment status, employment problems, financial problems, housing problems, living circumstances (alone/with others), and social isolation problems. Problems are defined clinically as difficulties facing an individual which cause current distress and/or contribute to the DSH episode. 


\section{Data management and statistical analyses}

In order to generate area clusters which would have reliable age- and sex-specific rates, wards were ordered according to Townsend scores and then divided into 20 approximately equal sized groups based on this ranking. The same grouping procedure was applied to the wards according to their social fragmentation scores. Mean annual age-standardized rates (across 10-year age bands) were calculated for DSH in males and females separately for the ward groups using Oxfordshire population data from the 1991 Census. Four broad age categories (15-24 years, 25-34 years, 35-54 years and 55 years and over) were used. Because of relatively small numbers, the suicide rates were not examined in separate age bands. Associations of rates of both DSH and suicide with socio-economic deprivation and social fragmentation scores were examined by conducting Pearson's product moment correlation and weighted least squares regression analyses (weighted according to ward group population size). The comparisons of the groups of patients from the high and low socioeconomic deprivation and social fragmentation ward groups were conducted using EpiInfo (Dean et al. 1994) to generate odds ratios and associated $95 \%$ confidence intervals.

\section{RESULTS}

\section{Study populations}

A total of $5899 \mathrm{DSH}$ patients presented to the general hospital from the catchment area over the study period. There were 453 suicides during this time (Table 1).

\section{Associations between DSH and suicide rates and socio-economic deprivation (Townsend Index)}

Strong associations were found between DSH rates and socio-economic deprivation scores across all three age groups in both males and females (see Table 2). These were strongest in the three youngest age groups. For suicides, a significant association was found for males overall but not for females (see Table 2).

The scatter plots in Fig. 1 illustrate the strong linear association between socio-economic deprivation and DSH rates in males and females. The regression coefficients given in Table 2 represent the increase in DSH rates (per 100000) per unit increase in Townsend scores. There was a significant interaction between gender and Townsend scores $\left(F_{1}=4 \cdot 32, \quad P<0.05\right)$, indicating that variations in socio-economic deprivation have a greater influence on male than female DSH rates. In males the regression coefficients were higher in the three younger age groups and in both genders the largest coefficient was in the 35-54 year age group.

For suicides there was little difference between the regression coefficients for males and females of all ages (Table 2).

\section{DSH and suicide rates and social fragmentation (anomie score)}

The associations between DSH rates and social fragmentation scores were of a similar pattern to those observed with socio-economic deprivation (Table 2). However, the regression coefficients indicate that the increase in DSH rates per unit increase in social fragmentation was smaller than in relation to socio-economic deprivation scores. Variations in social fragmentation influenced male DSH rates to a greater extent than female DSH rates, though this difference was not significant (interaction between gender and social fragmentation scores $\left(F_{1}=3 \cdot 05, P=\right.$ 0.089)). There was no significant association between social fragmentation and suicide in either males or females (Table 2).

\section{Multivariate analysis adjusting for Townsend and social fragmentation scores}

The socio-economic deprivation and social fragmentation scores for individual wards were highly correlated (Pearson's correlation coefficient $=0.70, P<0.001)$. Controlling for social fragmentation scores led to some attenuation of the correlations between DSH and socio-economic deprivation in both genders (Table 3) but had little effect on the magnitude of the regression coefficients. In contrast the strength of the associations between DSH and social fragmentation scores were much reduced after controlling for socio-economic deprivation (Table 3).

The observed associations between suicide and socio-economic deprivation found in males and females were also greatly attenuated after controlling for social fragmentation (Table 3). 
Table 1. Gender and age distributions of study populations

\begin{tabular}{|c|c|c|c|c|c|c|c|c|c|}
\hline & \multicolumn{3}{|c|}{ Males } & \multicolumn{3}{|c|}{ Females } & \multicolumn{3}{|c|}{ Total } \\
\hline & $N$ & $(\%)$ & Rate & $N$ & $(\%)$ & Rate & $N$ & $(\%)$ & Rate \\
\hline \multicolumn{10}{|c|}{ DSH patients } \\
\hline $15-24$ & 913 & $(38 \cdot 6)$ & $276 \cdot 3$ & 1634 & $(46 \cdot 2)$ & $519 \cdot 3$ & 2547 & $(43 \cdot 2)$ & $394 \cdot 8$ \\
\hline $25-34$ & 718 & $(30 \cdot 4)$ & 187.9 & 810 & $(22 \cdot 9)$ & 218.4 & 1528 & $(25.9)$ & $202 \cdot 9$ \\
\hline $35-54$ & 555 & $(23 \cdot 5)$ & $93 \cdot 5$ & 788 & $(22 \cdot 3)$ & $135 \cdot 2$ & 1343 & $(22 \cdot 8)$ & $114 \cdot 2$ \\
\hline$\geqslant 55$ & 178 & $(7.5)$ & 37.5 & 303 & $(8 \cdot 6)$ & 51.8 & 481 & $(8 \cdot 2)$ & $45 \cdot 4$ \\
\hline All ages & 2364 & (100) & $132 \cdot 7$ & 3535 & (100) & $190 \cdot 7$ & 5899 & (100) & $162 \cdot 3$ \\
\hline \multicolumn{10}{|l|}{ Suicides } \\
\hline $15-24$ & 62 & $(18 \cdot 2)$ & $18 \cdot 8$ & 12 & $(10 \cdot 7)$ & $4 \cdot 1$ & 74 & $(16 \cdot 3)$ & $11 \cdot 5$ \\
\hline $25-34$ & 68 & $(19 \cdot 9)$ & 17.8 & 18 & $(16 \cdot 1)$ & 4.9 & 86 & $(19 \cdot 0)$ & 11.4 \\
\hline $35-54$ & 114 & $(33 \cdot 4)$ & $19 \cdot 2$ & 35 & $(31 \cdot 3)$ & $6 \cdot 0$ & 149 & $(32 \cdot 9)$ & $12 \cdot 7$ \\
\hline$\geqslant 55$ & 97 & $(28 \cdot 5)$ & $20 \cdot 4$ & 47 & $(42 \cdot 0)$ & $8 \cdot 0$ & 144 & $(31 \cdot 8)$ & 13.6 \\
\hline All ages & 341 & (100) & $19 \cdot 1$ & 112 & (100) & $6 \cdot 0$ & 453 & (100) & $12 \cdot 5$ \\
\hline
\end{tabular}

Rate, i.e. per 100000 per year.

Table 2. Associations between (a) DSH rates and socio-economic deprivation (Townsend score) and social fragmentation, and (b) suicide rates and socio-economic deprivation and social fragmentation

\begin{tabular}{|c|c|c|c|c|c|c|}
\hline & \multicolumn{3}{|c|}{ Townsend } & \multicolumn{3}{|c|}{ Social Fragmentation } \\
\hline & $\begin{array}{l}\text { Pearson } \\
\text { correlation } \\
\text { coefficient }\end{array}$ & Regression coefficient $\dagger$ & $(95 \% \mathrm{CI})$ & $\begin{array}{l}\text { Pearson } \\
\text { correlation } \\
\text { coefficient }\end{array}$ & Regression coefficient $\dagger$ & $(95 \% \mathrm{CI})$ \\
\hline \multicolumn{7}{|l|}{ (a) $\mathrm{DSH}$} \\
\hline \multicolumn{7}{|l|}{ Males } \\
\hline $15-24$ & $0 \cdot 89^{* * *}$ & $28 \cdot 3$ & ( $22 \cdot 5$ to $34 \cdot 0$ ) & $0 \cdot 74^{* * *}$ & $10 \cdot 1$ & ( $6 \cdot 1$ to $14 \cdot 1)$ \\
\hline $25-34$ & $0.89 * * *$ & $32 \cdot 1$ & $(26 \cdot 0$ to $40 \cdot 2)$ & $0.84^{* * *}$ & $13 \cdot 1$ & $(8.9$ to $17 \cdot 2)$ \\
\hline $35-54$ & $0 \cdot 87^{* * *}$ & $46 \cdot 4$ & $(34 \cdot 3$ to $58 \cdot 4)$ & $0 \cdot 94 * * *$ & $19 \cdot 9$ & $(16 \cdot 2$ to $23 \cdot 6)$ \\
\hline$\geqslant 55$ & $0.58^{* *}$ & $17 \cdot 3$ & $(6 \cdot 2$ to $28 \cdot 3)$ & $0.47 *$ & 8.4 & $(2 \cdot 2$ to $14 \cdot 7)$ \\
\hline All ages & $0 \cdot 89^{* * *}$ & $29 \cdot 4$ & (22.6 to $36 \cdot 3)$ & $0 \cdot 83^{* * *}$ & $12 \cdot 6$ & $(9 \cdot 0$ to $16 \cdot 2)$ \\
\hline \multicolumn{7}{|l|}{ Females } \\
\hline $15-24$ & $0 \cdot 87^{* * *}$ & $17 \cdot 7$ & $(13.8$ to 21.5$)$ & $0 \cdot 77^{* * *}$ & $7 \cdot 6$ & ( 4.5 to 10.7$)$ \\
\hline $25-34$ & $0 \cdot 80^{* * *}$ & $20 \cdot 5$ & $(13.7$ to $27 \cdot 2)$ & $0 \cdot 63^{* *}$ & $7 \cdot 1$ & ( 2.9 to 11.4$)$ \\
\hline $35-54$ & $0 \cdot 85^{* * *}$ & $27 \cdot 6$ & $(20.4$ to 34.8$)$ & $0 \cdot 76^{* * *}$ & $9 \cdot 7$ & ( $5 \cdot 3$ to $14 \cdot 2$ ) \\
\hline$\geqslant 55$ & $0 \cdot 61^{* *}$ & 18.6 & $(9 \cdot 6$ to $27 \cdot 6)$ & $0 \cdot 69^{* *}$ & $11 \cdot 3$ & $(6 \cdot 2$ to $16 \cdot 4)$ \\
\hline All ages & $0 \cdot 87^{* * *}$ & $21 \cdot 3$ & (16.7 to $25 \cdot 9)$ & $0 \cdot 86^{* * *}$ & $9 \cdot 7$ & $(7 \cdot 0$ to $12 \cdot 4)$ \\
\hline \multicolumn{7}{|l|}{ (b) Suicide } \\
\hline \multicolumn{7}{|l|}{ Males } \\
\hline All ages & $0.79^{* * *}$ & $1 \cdot 3$ & $(0.8$ to 1.7$)$ & 0.38 & $0 \cdot 4$ & $(-0.1$ to 0.9$)$ \\
\hline \multicolumn{7}{|l|}{ Females } \\
\hline All ages & 0.37 & $1 \cdot 2$ & $(0 \cdot 2$ to $2 \cdot 8)$ & 0.39 & $0 \cdot 4$ & $(-0.1$ to 0.8$)$ \\
\hline
\end{tabular}

* $P<0.05 ; * * P<0.01 ; * * * P<0.001$.

Regression analysis is weighted by population size, therefore some regression coefficients are statistically significant where the associated correlation coefficient is not.

$\dagger$ Increase in DSH rate per 100000 associated with a one unit increase in that score.

\section{Characteristics of DSH patients}

To investigate whether the characteristics of individuals who self-harmed reflected those of their area of residence, personal characteristics of patients were examined for those living in groups of wards with the highest and lowest levels of socio-economic deprivation and social fragmentation. Among males and females selec- ted according to extreme high and low socioeconomic deprivation score ward groups, significantly greater proportions of those resident in the most deprived wards were unemployed or living alone. (Table 4). More females living in areas with high socio-economic deprivation had housing problems. Social isolation was also more frequently experienced by those of both genders in deprived areas, although this effect 

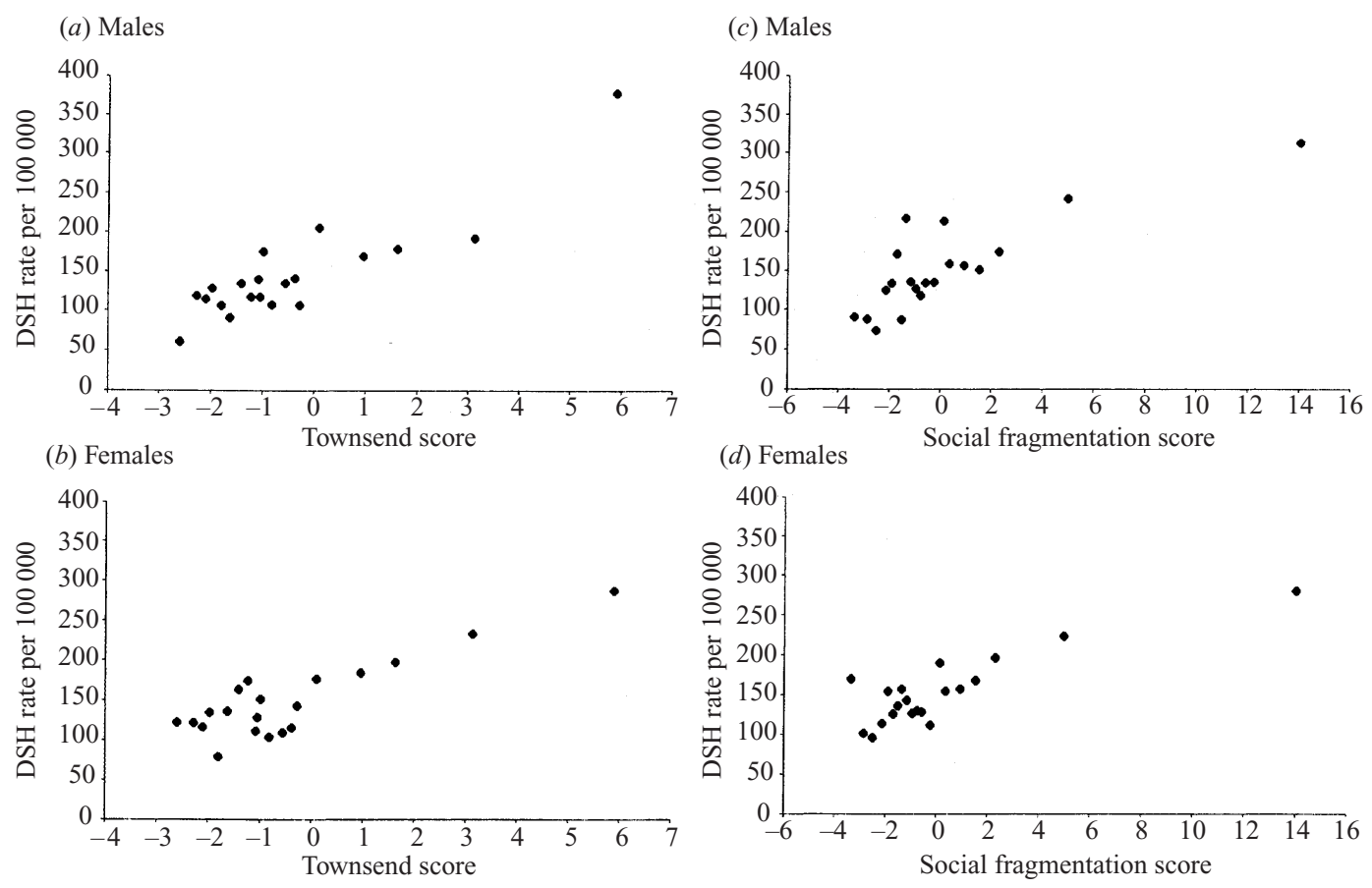

FIG. 1. Scatter plots of DSH rates by socio-economic deprivation (Townsend scores) for $(a)$ males and $(b)$ females, and by social fragmentation scores for $(c)$ males and $(d)$ females.

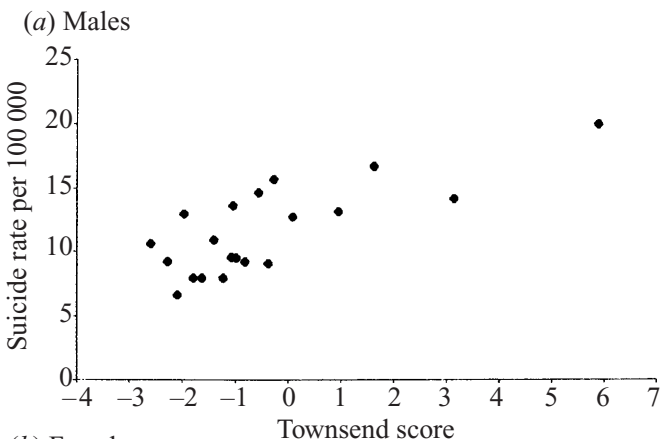

(c) Males

(b) Females
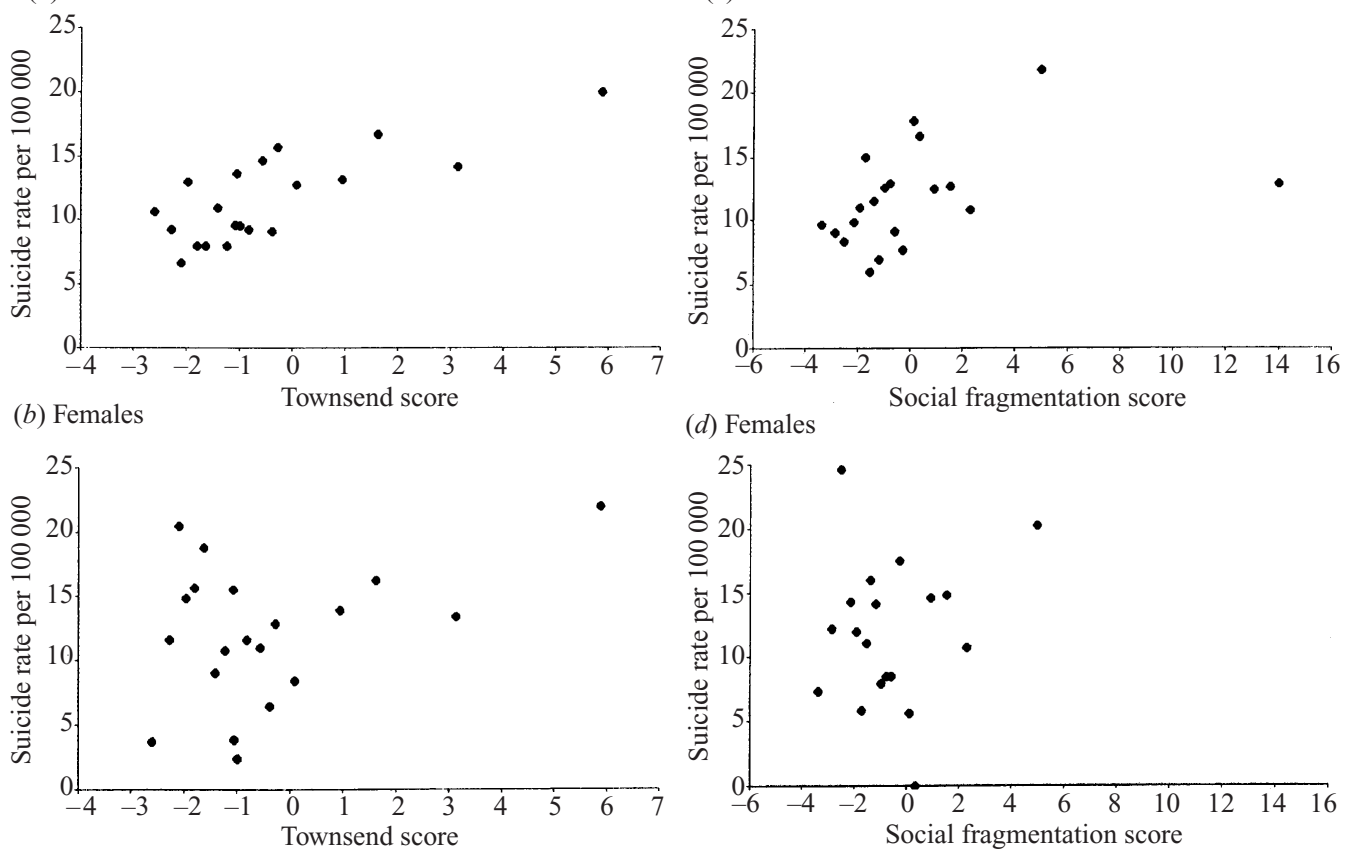

(d) Females

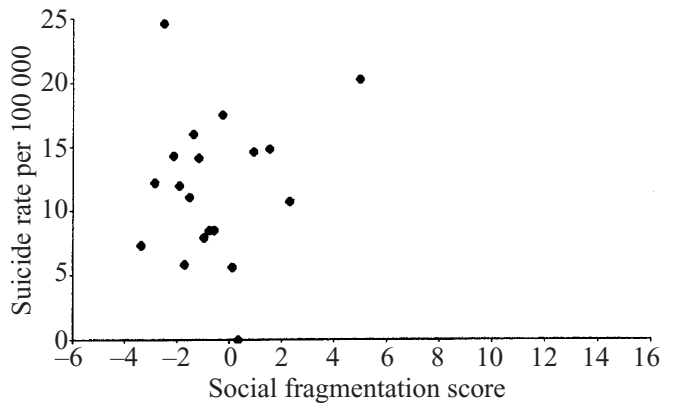

FIG. 2. Scatter plots of suicide rates by socio-economic deprivation (Townsend scores) for $(a)$ males and $(b)$ females, and by social fragmentation scores for $(c)$ males and $(d)$ females. 
Table 3. Partial associations between (a) DSH rates and socio-economic deprivation (Townsend score) and social fragmentation, and (b) suicide rates and socio-economic deprivation and social fragmentation

\begin{tabular}{|c|c|c|c|c|c|c|}
\hline & \multicolumn{3}{|c|}{$\begin{array}{c}\text { Townsend } \\
\text { (controlling for social fragmentation score) }\end{array}$} & \multicolumn{3}{|c|}{$\begin{array}{l}\text { Social fragmentation } \\
\text { (controlling for Townsend score) }\end{array}$} \\
\hline & $\begin{array}{c}\text { Partial } \\
\text { correlation } \\
\text { coefficient }\end{array}$ & Regression coefficient $\dagger$ & $(95 \% \mathrm{CI})$ & $\begin{array}{c}\text { Partial } \\
\text { correlation } \\
\text { coefficient }\end{array}$ & Regression coefficient & $(95 \% \mathrm{CI})$ \\
\hline \multicolumn{7}{|l|}{ (a) $\mathrm{DSH}$} \\
\hline \multicolumn{7}{|l|}{ Males } \\
\hline $15-24$ & $0 \cdot 59 * *$ & $36 \cdot 4$ & $(18 \cdot 1$ to $54 \cdot 8)$ & $-0 \cdot 26$ & $-3 \cdot 7$ & $(-13 \cdot 7$ to $6 \cdot 2)$ \\
\hline $25-34$ & $0 \cdot 58 * *$ & $41 \cdot 4$ & $(18 \cdot 8$ to $64 \cdot 0)$ & $0 \cdot 04$ & $-0 \cdot 8$ & $(-11 \cdot 1$ to $9 \cdot 5)$ \\
\hline $35-54$ & $0 \cdot 48^{*}$ & $52 \cdot 2$ & $(13 \cdot 1$ to $91 \cdot 3)$ & $0 \cdot 49 *$ & $14 \cdot 0$ & $(3 \cdot 0$ to $25 \cdot 1)$ \\
\hline$\geqslant 55$ & $0 \cdot 39$ & $31 \cdot 3$ & $(-3.9$ to $66 \cdot 5)$ & -0.07 & $1 \cdot 4$ & $(-17 \cdot 7$ to $20 \cdot 4)$ \\
\hline All ages & $0 \cdot 63 * *$ & $39 \cdot 4$ & $(17 \cdot 9$ to $61 \cdot 0)$ & 0.06 & $3 \cdot 9$ & $(-6 \cdot 2$ to $14 \cdot 0)$ \\
\hline \multicolumn{7}{|l|}{ Females } \\
\hline $15-24$ & $0 \cdot 42$ & $15 \cdot 2$ & ( $2 \cdot 8$ to $27 \cdot 7)$ & $-0 \cdot 13$ & $-3 \cdot 6$ & $(-11 \cdot 2$ to $4 \cdot 0)$ \\
\hline $25-34$ & $0 \cdot 41$ & $23 \cdot 1$ & $(1 \cdot 2$ to $45 \cdot 1)$ & $-0 \cdot 29$ & $-7 \cdot 8$ & $(-18 \cdot 2$ to $2 \cdot 7)$ \\
\hline $35-54$ & $0 \cdot 51^{*}$ & $34 \cdot 6$ & $(11.5$ to $57 \cdot 7)$ & $0 \cdot 05$ & $-2 \cdot 0$ & $(-14 \cdot 2$ to $10 \cdot 2)$ \\
\hline$\geqslant 55$ & $0 \cdot 32$ & $20 \cdot 3$ & $(-9 \cdot 0$ to $49 \cdot 6)$ & $0 \cdot 28$ & $12 \cdot 4$ & $(-3.4$ to $28 \cdot 2)$ \\
\hline All ages & $0 \cdot 56^{*}$ & $24 \cdot 1$ & $(9 \cdot 3$ to $38 \cdot 8)$ & $0 \cdot 19$ & $3 \cdot 1$ & $(-4.5$ to $10 \cdot 7)$ \\
\hline \multicolumn{7}{|l|}{ (b) Suicide } \\
\hline \multicolumn{7}{|l|}{ Males } \\
\hline All ages & $0 \cdot 14$ & $0 \cdot 7$ & $(-0 \cdot 2$ to $1 \cdot 7)$ & $-0 \cdot 27$ & -0.5 & $(-2.0$ to 0.9$)$ \\
\hline \multicolumn{7}{|l|}{ Females } \\
\hline All ages & $-0 \cdot 04$ & $1 \cdot 1$ & $(-1 \cdot 1$ to $3 \cdot 2)$ & $-0 \cdot 16$ & $-0 \cdot 3$ & $(-1.6$ to $1 \cdot 1)$ \\
\hline
\end{tabular}

* $P<0.05 ; * * P<0.01 ; * * * P<0.001$

Regression analysis is weighted by population size, therefore some regression coefficients are statistically significant where the associated correlation coefficient is not.

$\dagger$ Increase in DSH rate per 100000 associated with a one unit increase in Townsend score.

$\$$ Increase in DSH rate per 100000 associated with a one unit increase in social fragmentation score.

did not reach conventional levels of statistical significance. In contrast, significantly greater proportions of males living in wards with low socio-economic deprivation had financial problems (whereas in females there was a trend in the opposite direction).

Among patients selected on the basis of being resident in ward groups of extreme high or extreme low social fragmentation, significantly greater proportions of both males and females from areas of greater social fragmentation were unemployed or living alone. A significantly greater proportion of males living in areas of high social fragmentation were experiencing problems of social isolation compared with those resident in areas of low social fragmentation.

\section{DISCUSSION}

The first main finding of this study was that there was a close association between socioeconomic deprivation and DSH rates. This was particularly marked in young males. This indicates that areas characterized by high levels of socio-economic deprivation experience elevated rates of DSH, especially among middle-aged and younger males. A strong association between social fragmentation and DSH rates was also found. Multivariate analysis suggested that this effect was largely explained by the higher levels of socio-economic deprivation in socially fragmented areas.

Socio-economic deprivation was associated with suicide rates in males and females but the effects were attenuated by controlling for social fragmentation. Likewise, in both genders, the weak associations between social fragmentation and suicide were greatly attenuated after controlling for socio-economic deprivation. Congdon (1996), in his analysis of patterns of suicide in London, reported that the correlations of socio-economic deprivation with both suicide and DSH were higher in males than females. Our data provide some support for this observation. In Congdon's analysis while 
Table 4. Characteristics of DSH patients from selected wards with the highest and lowest (a) socio-economic deprivation (Townsend) and (b) social fragmentation scores

\begin{tabular}{|c|c|c|c|c|c|c|c|c|c|c|c|c|}
\hline & \multicolumn{6}{|c|}{ Wards grouped according to Townsend score } & \multicolumn{6}{|c|}{ Wards grouped according to social fragmentation score } \\
\hline & \multicolumn{2}{|c|}{ Highest } & \multicolumn{2}{|c|}{ Lowest } & \multirow{2}{*}{$\begin{array}{l}\text { Odds } \\
\text { ratio }\end{array}$} & \multirow[b]{2}{*}{$(95 \% \mathrm{CI})$} & \multicolumn{2}{|c|}{ Highest } & \multicolumn{2}{|c|}{ Lowest } & \multirow{2}{*}{$\begin{array}{l}\text { Odds } \\
\text { ratio }\end{array}$} & \multirow[b]{2}{*}{$(95 \% \mathrm{CI})$} \\
\hline & $n / N$ & $(\%)$ & $n / N$ & $(\%)$ & & & $n / N$ & $(\%)$ & $n / N$ & $(\%)$ & & \\
\hline \multicolumn{13}{|l|}{ Males } \\
\hline Unemployed & $369 / 662$ & (55.7) & $23 / 95$ & (24:2) & 3.94 & $(2 \cdot 36$ to $6 \cdot 77)$ & $283 / 481$ & (58.8) & $20 / 73$ & (27.4) & 3.79 & $(2 \cdot 14$ to $6 \cdot 89)$ \\
\hline $\begin{array}{l}\text { Total } \% \text { unemployed in area } \\
\text { Living alone }\end{array}$ & ${ }_{\mathbf{2 2 9} / 504}^{12 \cdot 48}$ & & $17 / 75^{4 \cdot 5}$ & $(22 \cdot 7)$ & & $(1.58$ to $5 \cdot 35)$ & $231 / 400^{9 \cdot 4}$ & & $6 / 54$ & $(11 \cdot 1)$ & & (4.51 to $31 \cdot 85)$ \\
\hline Employment problems & $205 / 473$ & $(43 \cdot 3)$ & $35 / 71$ & $(49 \cdot 3)$ & 0.79 & $(0.46$ to 1.34$)$ & $159 / 376$ & $(42 \cdot 3)$ & $26 / 47$ & $(55 \cdot 3)$ & $\begin{array}{r}10.93 \\
0.59\end{array}$ & $(0.30$ to $1 \cdot 14)$ \\
\hline Financial problems & $132 / 473$ & (27.9) & $30 / 71$ & $(42 \cdot 3)$ & 0.53 & $(0.31$ to 0.92$)$ & $90 / 376$ & $(23 \cdot 9)$ & $10 / 47$ & $(21 \cdot 3)$ & $1 \cdot 16$ & ( 0.54 to 2.73$)$ \\
\hline Housing problems & $112 / 473$ & $(23 \cdot 7)$ & $15 / 71$ & $(21 \cdot 1)$ & $1 \cdot 16$ & ( 0.61 to $2 \cdot 23)$ & $82 / 376$ & $(21 \cdot 8)$ & $9 / 47$ & $(19 \cdot 1)$ & $1 \cdot 49$ & $(0.68$ to 3.59$)$ \\
\hline Social isolation problems & $106 / 473$ & $(22 \cdot 4)$ & $9 / 71$ & $(12 \cdot 7)$ & 1.99 & $(0 \cdot 94$ to $4 \cdot 70)$ & $97 / 376$ & (25.8) & $4 / 47$ & $(8.5)$ & 3.74 & (1.30 to $14 \cdot 67)$ \\
\hline \multicolumn{13}{|l|}{ Females } \\
\hline Unemployed & $225 / 556$ & $(40.5)$ & $33 / 119$ & (27.7) & 1.77 & $(1.13$ to 2.83$)$ & $175 / 399$ & (43.9) & 21/91 & (23.1) & $\mathbf{2 \cdot 6 0}$ & $(1.51$ to 4.64$)$ \\
\hline Total $\%$ unemployed in area & 6.67 & & $2 \cdot 5$ & & & & $5 \cdot 9$ & & $3 \cdot 1$ & & & \\
\hline Living alone & $207 / 694$ & (29.8) & 21/132 & (15.9) & $2 \cdot 25$ & (1.35 to 3.88$)$ & $244 / 555$ & (44:0) & $16 / 125$ & (12:8) & 5.34 & (3.04 to 9.92$)$ \\
\hline Employment problems & $205 / 624$ & $(32 \cdot 9)$ & $41 / 121$ & (33.9) & 0.95 & ( 0.62 to 1.48$)$ & $180 / 499$ & $(36 \cdot 1)$ & $33 / 112$ & $(29 \cdot 5)$ & $1 \cdot 35$ & ( $0 \cdot 85$ to $2 \cdot 18)$ \\
\hline Financial problems & $130 / 624$ & $(20 \cdot 8)$ & $16 / 121$ & $(13 \cdot 2)$ & 1.73 & $(0.97$ to 3.24$)$ & $88 / 499$ & $(17 \cdot 6)$ & $20 / 112$ & $(17.9)$ & 0.98 & ( 0.57 to 1.78$)$ \\
\hline Housing problems & $117 / 624$ & (18.8) & $13 / 121$ & $(10 \cdot 7)$ & 1.92 & (1.03 to 3.84$)$ & $86 / 499$ & $(17 \cdot 2)$ & $14 / 112$ & $(12.5)$ & $1 \cdot 46$ & ( 0.78 to $2 \cdot 90)$ \\
\hline Social isolation problems & $136 / 624$ & $(21 \cdot 8)$ & $21 / 121$ & $(17 \cdot 4)$ & 1.33 & (0.79 to 2.32$)$ & $113 / 499$ & $(22 \cdot 6)$ & $18 / 112$ & $(16 \cdot 1)$ & 1.53 & ( 0.87 to $2 \cdot 81)$ \\
\hline
\end{tabular}

The odds ratio presented here estimates the relative odds of an individual having each characteristic examined in this Table if they live in a ward with a high Townsend or social fragmentation

score respectively.
Figures in bold type represent findings that are statistically singificant at $P \leqslant 0 \cdot 05$. 
associations between social fragmentation (anomie) and DSH were relatively weak they were stronger for suicide, particularly in females. We found the opposite, with stronger associations between social fragmentation and DSH than with suicide, with similar effects in males and females. It is possible that these contrasting findings reflect different influences on suicide according to geographical location (i.e. entirely urban London wards versus mixed rural-urban areas in Oxfordshire). In their study of the whole of Britain, Whitley et al. (1999) reported an association between suicide rates and social fragmentation in both genders. Differences between their findings and those reported here may reflect differences in the size of the areas studied, as ecological associations may differ at different levels of aggregation (Piantadosi et al. 1988). Alternatively, the greater range and diversity of social fragmentation across the entire country, together with the greater statistical power of an analysis based on over 600 districts, may be important in explaining the different findings.

Some of the ecological associations for DSH were borne out by associations at the individual patient level. These results represent an important new finding in this field. More of the DSH patients of both genders living in areas of high socio-economic deprivation were unemployed, living alone, and having problems with housing, compared with those from areas of low deprivation. Financial problems were, however, more common in males from less deprived areas, suggesting that for this factor dissonance between the characteristics of the individual and those living in the same area may increase risk of DSH, as has also been found in the UK for ethnicity (Neeleman \& Wessely, 1999). Both male and female DSH patients from areas of high social fragmentation were more likely to be unemployed or living alone than those from less fragmented areas, and more males from these areas were experiencing problems of social isolation. Thus, for most of these factors the patient characteristics were in keeping with the characteristics of the areas in which they lived.

\section{Methodological issues}

This study included a very large number of DSH patients, who represented a comprehensive sample of cases presenting to the general hospital, including patients discharged directly from the Accident and Emergency Department and those not assessed by the general hospital's psychiatric service. This is an improvement on previous studies (Gunnell et al. 1995; Congdon 1996). However, the much smaller sample of suicides in the present study may have limited its power to allow replication of some of the earlier findings for suicide.

We included most open verdicts in our analysis of suicide mortality as the majority of these are probable suicides (Charlton et al. 1992). In Oxford there is no difference in distribution of suicides and open verdicts according to social class (unpublished data), which is an indirect indicator of socio-economic status. While we omitted open verdict cases which were clearly not suicides (see Method section), the inclusion of some non-suicides may have influenced our effect estimates.

One disadvantage of our study is that the large student population of Oxford may have caused some distortion of socio-economic deprivation and social fragmentation scores because of the relatively low rates of car ownership among students, their tendency to live in highoccupancy, rented accommodation, and to change address relatively frequently. However, this potential problem has been dealt with as far as possible by our elimination of special EDs, including colleges, from the analysis, although a substantial proportion of students live in accommodation outside colleges in areas that were included.

Our findings are unlikely to be influenced by similarity of exposure in adjacent geographical areas (spatial auto-correlation), as the method of grouping meant that individual ward groups rarely included wards that were geographically proximate. Additionally, spatial autocorrelation is not thought to be an important problem with ecological studies of suicide (Wasserman \& Stack, 1995).

\section{Implications}

The results of this study are clearly relevant to the suicide target in Saving Lives: Our Healthier Nation (Department of Health, 1999a) and the aims of the National Service Framework: Mental Health (Department of Health, 1999b). Both of these strategy documents place emphasis on reducing inequalities in health and targeting 
initiatives at high-risk areas. The results of this study would suggest that a reduction in socioeconomic deprivation within deprived areas would be likely to result in a reduction in rates of suicidal behaviour, particularly in young men. Such a strategy clearly presents considerable challenges. In evaluation of any preventive initiatives it would be valuable to examine changes over time in the associations investigated in this study.

This project was funded by a grant from South East Region NHS Executive Research and Development Committee. Keith Hawton was also supported by Oxfordshire Mental Healthcare NHS Trust and Karen Hodder was supported by Oxfordshire Health Authority Department of Public Health. We thank Joan Fagg for her participation in the initial phase of this study, Elizabeth Bale, Alison Bond and the staff of the Department of Psychological Medicine at the John Radcliffe Hospital for their assistance with the data collection, and Ed Juszczak for statistical advice.

\section{REFERENCES}

Charlton, J., Kelly, S., Dunnell, K., Evans, B., Jenkins, R. \& Wallis, R. (1992). Trends in suicide deaths in England and Wales. Population Trends 69, 10-16.

Congdon, P. (1996). Suicide and parasuicide in London: a small area-study. Urban Studies 33, 137-158.

Dean, A. G., Dean, J. A., Coulombier, D., Brendel, K. A., Smith, D. C., Burton, A. H., Dicker, R. C., Sullivan, K., Fagan, R. F. \& Arner, T. G. (1994). EpiInfo Version 6: A Word Processing Database and Statistics Program for Epidemiology on Microcomputers. Centers for Disease Control \& Prevention: Atlanta, Georgia.

Department of Health (1999a). Saving Lives: Our Healthier Nation: A Contract for Health. CM 4386. The Stationery Office: London.

Department of Health (1999b). National Service Framework: Mental Health. Department of Health: London.

Durkheim, E. (1951). Suicide. Free Press: Glencoe, Illinois.

Greenland, S. \& Morgenstern, N. (1989). Ecological bias, confounding, and effect modification. International Journal of Epidemiology 18, 269-274.
Gunnell, D., Peters, T., Kammerling, R. \& Brooks, J. (1995). Relation between parasuicide, suicide, psychiatric admissions, and socio-economic deprivation. British Medical Journal 311, 226-230.

Gunnell, D., Lopatatzidis, A., Dorling, D., Wehner, H., Southall, H. \& Frankel, S. (1999). Suicide and unemployment in young people. Analysis of trends in England and Wales, 1921-1995. British Journal of Psychiatry 175, 263-270.

Hawton, K., Fagg, J., Simkin, S., Bale, E. \& Bond, A. (1997). Trends in deliberate self-harm in Oxford, 1985-1995. Implications for clinical services and the prevention of suicide. British Journal of Psychiatry 171, 556-560.

Hawton, K. \& Rose, N. (1986). Attempted suicide and unemployment among men in Oxford. Health Trends 2, 29-32.

Hintikka, J., Kontula, O., Saarinen, P., Tanskanen, A., Koskela, K. \& Viinamäki, H. (1998). Debt and suicidal behaviour in the Finnish general population. Acta Psychiatrica Scandinavica 98, 493-496.

Kreitman, N., Carstairs, V. \& Duffy, J. (1991). Association of age and social class with suicide among men in Great Britain. Journal of Epidemiology and Community Health 45, 195-202.

Lewis, G. \& Sloggett, A. (1998). Suicide, deprivation, and unemployment: record linkage study. British Medical Journal 317, 1283-1286.

Neeleman, J. \& Wessely, S. (1999). Ethnic minority suicide: a small area geographical study in south London. Psychological Medicine 29, 429-436.

Office for National Statistics (1995). Public Health Mortality File. Office for National Statistics: London.

Piantadosi, S., Byar, D. P. \& Green, S. B. (1988). The ecological fallacy. American Journal of Epidemiology 127, 893-904.

Platt, S. \& Hawton, K. (2000). Suicidal behaviour and the labour market. In The International Handbook of Suicide and Attempted Suicide (ed. K. Hawton and C. Van Heeringen), pp. 303-378. Wiley: Chichester.

Platt, S., Hawton, K., Kreitman, N., Fagg, J. \& Foster, J. (1988). Recent clinical and epidemiological trends in parasuicide in Edinburgh and Oxford: a tale of two cities. Psychological Medicine 18, 405-418.

Platt, S. \& Kreitman, N. (1984). Trends in parasuicide and unemployment among men in Edinburgh. British Medical Journal 289, 1029-1032.

Pritchard, C. (1992). Is there a link between suicide in young men and unemployment? A comparison of the UK with other European Community countries. British Journal of Psychiatry 160, 750-756.

Sellar, C., Goldacre, M. J. \& Hawton, K. (1990). Reliability of routine hospital data on poisoning as measures of deliberate self poisoning in adolescents. Journal of Epidemiology and Community Health 44, 313-315.

Wasserman, I. M. \& Stack, S. (1995). Geographical spatial autocorrelation and United States suicide patterns. Archives of Suicide Research 1, 121-129.

Whitley, E., Gunnell, D., Dorling, D. \& Davey Smith, G. (1999). Ecological study of social fragmentation, poverty, and suicide. British Medical Journal 319, 1034-1037. 